\title{
Cost-effectiveness of magnetic resonance imaging of the knee for patients presenting in primary care
}

\author{
DAMASK (Direct Access to Magnetic Resonance Imaging:
} Assessment for Suspect Knees) Trial Team

\begin{abstract}
Background

Musculoskeletal problems generate high costs. Of these disorders, patients with knee problems are commonly seen by GPs. Magnetic resonance imaging (MRI) of the knee is an accurate diagnostic test, but there is uncertainty as to whether GP access to MRI for these patients is a cost-effective policy.
\end{abstract}

Aim

To investigate the cost-effectiveness of GP referral to early MRI and a provisional orthopaedic appointment, compared with referral to an orthopaedic specialist without prior MRI for patients with continuing knee problems.

Design of study

Cost-effectiveness analysis alongside a pragmatic randomised trial.

Setting

Five-hundred and thirty-three patients consulting their GP about a knee problem were recruited from 163 general practices at 11 sites across the UK.

\section{Method}

Two-year costs were estimated from the NHS

perspective. Health outcomes were expressed in terms of quality-adjusted life years (QALYs), based on patient responses to the $E Q-5 D$ questionnaire administered at baseline, and at 6, 12, and 24 months' follow-up.

\section{Results}

Early MRI is associated with a higher NHS cost, by $£ 294$ (\$581; €435) per patient (95\% confidence interval $[\mathrm{Cl}]=£ 31$ to $£ 573$ ), and a larger number of QALYs, by $0.050(95 \% \mathrm{Cl}=-0.025$ to 0.118$)$. Mean differences in cost and QALYs generated an incremental cost per QALY gained of $£ 5840$ ( $\$ 11538 ; € 8642$ ). At a cost per QALY threshold of $£ 20000$, there is a 0.81 probability that early MRI is a cost-effective use of NHS resources.

\section{Conclusion}

GP access to MRI for patients presenting in primary care with a continuing knee problem represents a costeffective use of health service resources.

\section{Keywords}

cost-benefit analysis; family practice; knee injuries; magnetic resonance imaging.

\section{INTRODUCTION}

Musculoskeletal problems and associated disabilities generate high costs - in health care (both within and outside the NHS), social security, and lost production. ${ }^{1}$ Each year in the UK, $15 \%$ of patients who consult GPs do so for musculoskeletal disorders. ${ }^{2}$ The annual consulting rate in primary care for internal derangement of the knee is 32 per 1000 patient-years, similar to rheumatoid arthritis. ${ }^{2}$ For this condition, a GP could refer the patient to a hospital specialist who might order a magnetic resonance imaging (MRI) scan and may then perform arthroscopic surgery for possibly therapeutic purposes. This procedure is invasive with possible complications of surgery and therefore costly, both in financial terms and in terms of pain and discomfort to patients. ${ }^{3}$ Systematic reviews have demonstrated that MRI is sensitive and specific for detecting lesions of the cruciate ligaments and menisci compared with arthroscopic procedures. ${ }^{4,5}$ The use of MRI by GPs to diagnose and manage patients with suspected internal derangement of the knee could result in the avoidance of unnecessary hospital referrals and arthroscopy. This, however, could lead to overburdening of limited MRI resources, resulting in extended waiting times and increased medical costs. $^{3}$

DAMASK (Direct Access to Magnetic Resonance Imaging: Assessment for Suspect Knees) Trial Team, York Trials Unit, Department of Health Sciences, University of York, York.

Address for correspondence

Professor Stirling Bryan, Department of Health Economics, Occupational Health Building, University of Birmingham,

Birmingham, West Midlands, B15 2TT.

E-mail: s.bryan@bham.ac.uk

Submitted: 14 March 2008; Editor's response: 6 May 2008; final acceptance: 18 August 2008.

oBritish Journal of General Practice.

This is the full-length article of an abridged version published in print. Cite this article as: $\mathrm{Br} J$ Gen Pract 2008; DOI: $10.3399 /$ bjgp08X342660. 
Nearly one million MRI examinations are performed in England each year, and this MRI provision is expected to rise, with an investment to upgrade diagnostics in the NHS. ${ }^{6-8} \mathrm{MRI}$ of the knee has been found to be an accurate examination, but little evidence exists for the effectiveness of GP referral for knee MRI. Watura et al compared findings of MRI of the knee in 165 patients referred by GPs with 470 patients referred by orthopaedic teams. They found no significant differences between the two referral pathways in normal or abnormal MRI scans. ${ }^{9}$ There is also little evidence for the costeffectiveness of GP access to MRI in primary care. A small trial conducted in the UK compared MRI and arthroscopy for patients attending routine orthopaedic clinics and found no significant differences in either health outcomes or costs between groups. ${ }^{10}$ In secondary care there is evidence that MRI of the knee can help to reduce expense. An Austrian study found that MRI was more accurate than orthopaedic clinical examination at diagnosing meniscal lesions, and MRI examinations could save money by avoiding diagnostic arthroscopies. ${ }^{11}$ A study in Canada conducted a decision tree analysis of the use of MRI among patients requiring arthroscopy of the knee, and found MRI appeared to be a cost-effective diagnostic procedure. $^{3}$

Given the uncertainty about whether MRI of the knee should enter the diagnostic pathway in primary care, through early access for GPs, or be restricted to secondary care at the request of orthopaedic specialists, a broad economic evaluation is timely to inform commissioning and service-configuration questions about the most efficient policy for the use of MRI. The present research carried out a trialbased economic analysis to assess the costeffectiveness of direct access to MRI as compared to orthopaedic referral for patients with suspected knee derangement. The accompanying effectiveness paper reports whether GPs' use of MRI for patients with suspected internal derangement of the knee improves their general physical or knee-related health. ${ }^{12}$

\section{METHOD}

The trial design and methods have been described in detail elsewhere. ${ }^{13}$ In brief, 553 eligible and consenting patients were recruited from 163 general practices between November 2002 and October 2004, and randomised to one of the two trial interventions:

- referral from the GP to the local radiology department for an MRI examination, the findings of which were used by the GP to inform their

\section{How this fits in}

Imaging of the knee is a common musculoskeletal application of magnetic

resonance imaging (MRI), and its provision is increasing. There is currently very

little evidence concerning the cost-effectiveness of GP access to MRI in primary

care. Compared to routine referral to an orthopaedic specialist, GP referral to

MRI is associated with a higher NHS cost and an improved health-related

quality of life for patients with suspected knee derangement. Overall, early MRI

represents a cost-effective use of healthcare resources.

diagnosis and plan for subsequent management;

- standard care involving referral to the local orthopaedic department for consultation with a specialist who may or may not subsequently request an $\mathrm{MRI}$ examination.

Before randomisation, all participants completed a baseline questionnaire asking about knee-related health, general health, and demographic characteristics. All patients were followed by postal questionnaires for 2 years after randomisation, at 6 , 12, and 24 months.

\section{Health outcomes}

For the cost-effectiveness analysis (CEA), kneerelated outcomes and health-related quality of life (HRQoL) were measured using the generic EuroQol EQ-5D instrument. The trial also used a kneespecific instrument (KQoL-26) and the SF-36 (Short Form-36). For each patient, utility scores were estimated at baseline, 6, 12, and 24 months, by converting the responses to the EQ-5D questionnaire using the EQ-5D UK social tariff. ${ }^{14}$ Under the assumption that utility changes in a linear fashion over time, a quality-adjusted life year (QALY) score was generated for each patient, by calculating the area beneath the curve that links each patient's utility scores at baseline, 6,12 , and 24 months. ${ }^{15}$

\section{Resource use}

Knee-related NHS resource-use data were collected by patient self-report questionnaires administered at 6, 12, and 24 months. Data collected included primary care consultations, MRI examinations, hospital visits and admissions, use of knee-related equipment, and use of pharmaceuticals. The perspective for the analysis reported here is the NHS, and so private and other societal costs/resources are not considered.

\section{Costs}

To value the use of resources, unit cost estimates were taken from a combination of local and national sources. For outpatient appointments, admissions to hospital, and use of equipment and medication, unit 


\section{Table 1. Unit costs.}

\begin{tabular}{|c|c|c|}
\hline Health care resource & Cost, $£$ & Source \\
\hline \multicolumn{3}{|l|}{ Primary care resources } \\
\hline GP & 24.00 & Curtis and Netten, $2005^{11}$ \\
\hline Practice nurse & 10.00 & Curtis and Netten, $2005^{11}$ \\
\hline Physiotherapist & 20.00 & Curtis and Netten, $2005^{11}$ \\
\hline \multicolumn{3}{|l|}{ NHS hospital resources } \\
\hline MRI examination & 290.17 & Study data \\
\hline \multicolumn{3}{|l|}{ Outpatient attendances $^{\mathrm{a}}$} \\
\hline First outpatient attendance & 134.00 & NHS Reference Costs, $2005^{12}$ \\
\hline Follow-up outpatient attendance & 82.00 & NHS Reference Costs, $2005^{12}$ \\
\hline Admission to NHS hospital & 1384.00 & NHS Reference Costs, $2005^{12}$ \\
\hline Physiotherapist & 46.00 & Curtis and Netten, $2005^{11}$ \\
\hline \multicolumn{3}{|l|}{ Equipment } \\
\hline Tubigrip $^{\circledast}$ & 2.83 & British National Formulary, $2006^{13}$ \\
\hline Knee brace & 20.00 & Study data \\
\hline \multicolumn{3}{|l|}{ Medication } \\
\hline Ibuprofen (400 mg) & 2.66 & British National Formulary, $2006^{13}$ \\
\hline
\end{tabular}

ancluding orthopaedic consultations. MRI = magnetic resonance imaging

costs were applied from published national sources. ${ }^{16-18}$ For the MRI examinations, estimates were obtained from a number of hospitals participating in the trial, and a mid-point estimate was used for the analysis. All unit costs used in this analysis are reported in Table 1, using a common 2005/2006 price year. Since the follow-up period was more than one year, year 2 costs (and QALYs) were discounted at an annual rate of $3.5 \%,{ }^{19}$ assuming that all costs are incurred at the start of each year. ${ }^{20}$

\section{Statistical analysis}

All data analysis was on an intention-to-treat basis. For each patient with complete data, estimates were made of a QALY score and a total NHS resource use cost by multiplying resource use with appropriate unit cost estimates over the 2 years' follow-up period. Mean differences in costs and QALYs between trial arms were calculated and, due to the observation of skewed cost and QALY distributions,

\section{Table 2. Baseline characteristics.}

\begin{tabular}{lccc} 
Characteristics & $\begin{array}{c}\text { MRI group } \\
(n=206)\end{array}$ & $\begin{array}{c}\text { Orthopaedic group } \\
(n=180)\end{array}$ & $\begin{array}{c}\text { Total } \\
(n=386)\end{array}$ \\
\hline Sex, \% male & 66 & 57 & 62 \\
\hline Ethnicity, \% white & 98.5 & 98.3 & \\
\hline Employed, \% & 93.2 & 89.9 & \\
\hline Mean age in years, (SD) & $40.8(10.2)$ & $40.7(10.2)$ & $40.8(10.2)$ \\
\hline Mean EQ-5D score, (SD) & $0.591(0.257)$ & $0.604(0.244)$ & $0.597(0.251)$ \\
\hline $\begin{array}{l}\text { Days off work in last 4 weeks due to } \\
\text { knee problem, median (IQR) }\end{array}$ & $0(0-5)$ & $0(0-4)$ & $0(0-4.25)$ \\
\hline $\begin{array}{l}\text { Days prevented from doing normal } \\
\text { activities in last 4 weeks, median (IQR) }\end{array}$ & $7(2-15.5)$ & $8(2-20)$ & $8(2-16)$ \\
\hline $\begin{array}{l}\text { IQR }=\text { interquartile range. } \\
\text { n }\end{array}$ & & & \\
\hline
\end{tabular}

non-parametric $95 \%$ confidence intervals (Cls) were estimated by employing the bias corrected and accelerated bootstrap method (1000 replications). ${ }^{21,22}$ As the research aimed to determine the differences in costs and QALYs between trial arms, an incremental analysis was undertaken to calculate and quantify these differences in the form of an incremental costeffectiveness ratio (ICER), a measure that determines the extra cost for one additional QALY. To account for inherent uncertainty due to sampling variation, nonparametric bootstrapping was used to derive 5000 paired estimates of mean differential cost and QALY scores. These estimates were then represented graphically on a cost-effectiveness plane, and costeffectiveness acceptability curves (CEACs) were plotted, showing the probability of direct access to MRI being cost-effective across a range of possible values of willingness to pay for an additional QALY. ${ }^{23,24}$

In line with recent recommendations, and to avoid biased estimates of QALY scores, the analysis also controlled for any possible between-group imbalance in baseline utility, using a regressionbased adjustment method. ${ }^{25}$ This was undertaken as a sensitivity analysis. Additional sensitivity analyses included:

- assuming fewer first outpatient appointments in the MRI arm (50\% fewer);

- assuming a lower unit cost for MRI (by 30\%).

The former was undertaken in recognition that the trial design (whereby all trial patients were booked for an outpatient appointment) may have inflated the number of appointments in the MRI arm.

\section{RESULTS}

Complete data were available for 386 patients $(70 \%$ of total sample) and this formed the sample for the base-case analysis. Baseline characteristics for the sample included in the cost-effectiveness analysis are reported in Table 2. Of the 167 patients who did not provide complete data, 143 failed to return one or more questionnaires, and 24 returned the questionnaires but failed to provide complete data for all the requested items. The base-case results are reported in Tables 3 and 4, including resource use, costs and QALYs by trial arm. These tables show that patients in the early MRI arm are associated with a significantly higher NHS cost, of approximately £295 per patient. This higher cost for early MRI is driven in part by a higher number of primary care consultations and more use of physiotherapy, but largely results simply from the greater use of MRI.

Figure 1 reports the mean estimates of EQ-5D plotted for baseline and all follow-up periods, by trial 
arm. At baseline, the mean (standard deviation [SD]) EQ-5D score was 0.591 (0.257) for the early MRI arm, and 0.604 (0.244) for the orthopaedic referral arm. Figure 1 indicates that health-related quality of life improved over time for patients in both arms of the trial but the improvement was significantly greater for patients who had early access to MRI. This small health benefit translates as a higher QALY score of about 0.05 , and putting the incremental cost and QALY scores together gives an ICER of $£ 5840$ per QALY gained.

Figure 2 shows the cost-effectiveness plane for the base-case. Each point results from a separate bootstrap replication, with 5000 points shown on the plane. The figure indicates the uncertainty around the base-case ICER but reveals that the vast majority of bootstrap results (approximately 90\%) are in the north-east quadrant, with both a positive cost and a positive QALY score. Figure 3 presents the CEAC curve, revealing that at a conventional cost per QALY threshold of $£ 20000$, there is a 0.81 probability that early MRI is a cost-effective use of NHS resources. ${ }^{25}$

When, as a sensitivity analysis, there is an adjustment for baseline utility differences between trial arms, the results reveal even stronger support for early MRI (Table 4). The ICER for this adjusted analysis is $£ 4800$ per QALY gained and, as shown in Figure 3 , the probability of early MRI being costeffective at $£ 20000$ per QALY gained is 0.93 . Table 4 also shows the results for the sensitivity analyses looking at outpatient visit rates and unit cost of MRI. The results are robust to these variations - similar incremental costs are reported for all analyses.

\section{DISCUSSION}

\section{Summary of main findings}

The early use of MRI in a primary care setting, for patients presenting with suspected knee derangement, is associated with a small but statistically significant improvement in health-related quality of life, as measured by the EQ-5D. However, the gain comes at a price of approximately $£ 300$ per patient and so a judgement call is required in terms of whether the benefit, of approximately 0.05 QALYs per patient, justifies the additional financial burden to the NHS. The resulting ICER of between $£ 5000$ and $£ 6000$ per QALY gained is well below the threshold of $£ 20000$ commonly viewed as good value for money in the UK NHS. ${ }^{26}$ This conclusion is confirmed by a probability of greater than $80 \%$ that early MRI represents a cost-effective use of health sector resources.

\section{Strengths and limitations of the study}

The major strength of this study lies in the fact that the analysed data were obtained from a large,
Table 3. Mean (SD) resource use and costs by treatment arm over 24 months.

Resource use and costs

\begin{tabular}{lcc}
\hline & $\begin{array}{c}\text { Early MRI } \\
(n=206)\end{array}$ & $\begin{array}{c}\text { Orthopaedic referral } \\
(n=180)\end{array}$ \\
\hline Primary care & & \\
Appointments with GP & $1.84(2.93)$ & $1.71(2.55)$ \\
Appointments with nurse & $0.27(0.82)$ & $0.13(0.44)$ \\
Appointments with physiotherapist & $2.63(6.05)$ & $2.19(4.43)$ \\
Appointments with other professional & $0.10(0.38)$ & $0.09(0.36)$ \\
Total NHS primary care cost, $£$ & $101.91(163.74)$ & $83.37(135)$ \\
\hline Secondary care & & \\
Outpatient appointments ${ }^{\mathrm{b}}$ & $1.75(1.85)$ & $1.78(2.02)$ \\
Admissions to NHS hospital & $0.36(0.62)$ & $0.36(0.64)$ \\
Appointments with physiotherapists & $3.82(8.76)$ & $2.79(4.08)$ \\
$\quad$ in NHS hospitals & & $0.1(0.45)$ \\
Appointments with other health & $0.09(0.47)$ & \\
$\quad$ professionals in NHS hospitals & & $235.19(389.03)$ \\
\hline Total NHS secondary care cost, ${ }^{\mathrm{a}} £$ & $297.15(705.09)$ & $128.96(229.98)$ \\
MRI examination cost, $£$ & $326.79(157.92)$ & $1.59(5.70)$ \\
Equipment cost, $£$ & $1.99(5.28)$ & $4.55(7.90)$ \\
Medication cost, $£$ & $3.43(6.20)$ & $1021.46(1178.65)$ \\
\hline Total NHS cost, $£$ & $1315.47(1370.51)$
\end{tabular}

${ }^{a}$ Excluding MRI examinations. Including orthopaedic consultations. $M R I=$ magnetic resonance imaging.

multicentre randomised trial with a rigorous and pragmatic design. The trial sought to minimise the bias in the comparison of treatment arms, and such a trial is generally considered to be the best source of clinical and economic data for assessing healthcare interventions. ${ }^{20}$ Further, the data have been analysed using well-established statistical methods, and methodological and statistical uncertainty has also been explored.

Nonetheless, the study has some limitations. First, the assessment included only resource use and

Table 4. Mean (SD) costs and QALYs by treatment group over 24 months.

\begin{tabular}{|c|c|c|c|c|}
\hline & Early MRI & $\begin{array}{l}\text { Orthopaedic } \\
\text { referral }\end{array}$ & Difference & $\begin{array}{c}\text { Non-parametric } \\
95 \% \mathrm{Cl}^{\mathrm{a}}\end{array}$ \\
\hline $\begin{array}{l}\text { Mean cost over } \\
24 \text { months, } £\end{array}$ & $\begin{array}{c}1315 \\
(1370)\end{array}$ & $\begin{array}{c}1021 \\
(1178)\end{array}$ & 294 & 31 to 573 \\
\hline $\begin{array}{l}\text { Mean QALYs over } \\
24 \text { months }\end{array}$ & $\begin{array}{l}1.444 \\
(0.347) \\
\end{array}$ & $\begin{array}{c}1.393 \\
(0.377) \\
\end{array}$ & 0.050 & -0.025 to 0.118 \\
\hline \multicolumn{5}{|l|}{ Sensitivity analyses } \\
\hline $\begin{array}{l}\text { Mean QALYs (adjusted for } \\
\text { differences in baseline utility) }\end{array}$ & 1.449 & 1.387 & 0.061 & 0.005 to 0.117 \\
\hline $\begin{array}{l}\text { Mean cost, } £ \text { (assuming } \\
50 \% \text { fewer outpatient } \\
\text { visits in MRI group) }\end{array}$ & 1289 & 1021 & 268 & 13 to 523 \\
\hline $\begin{array}{l}\text { Mean cost, } £ \text { (assuming } \\
30 \% \text { lower MRI cost) }\end{array}$ & 1218 & 983 & 234 & $-£ 16$ to 485 \\
\hline
\end{tabular}




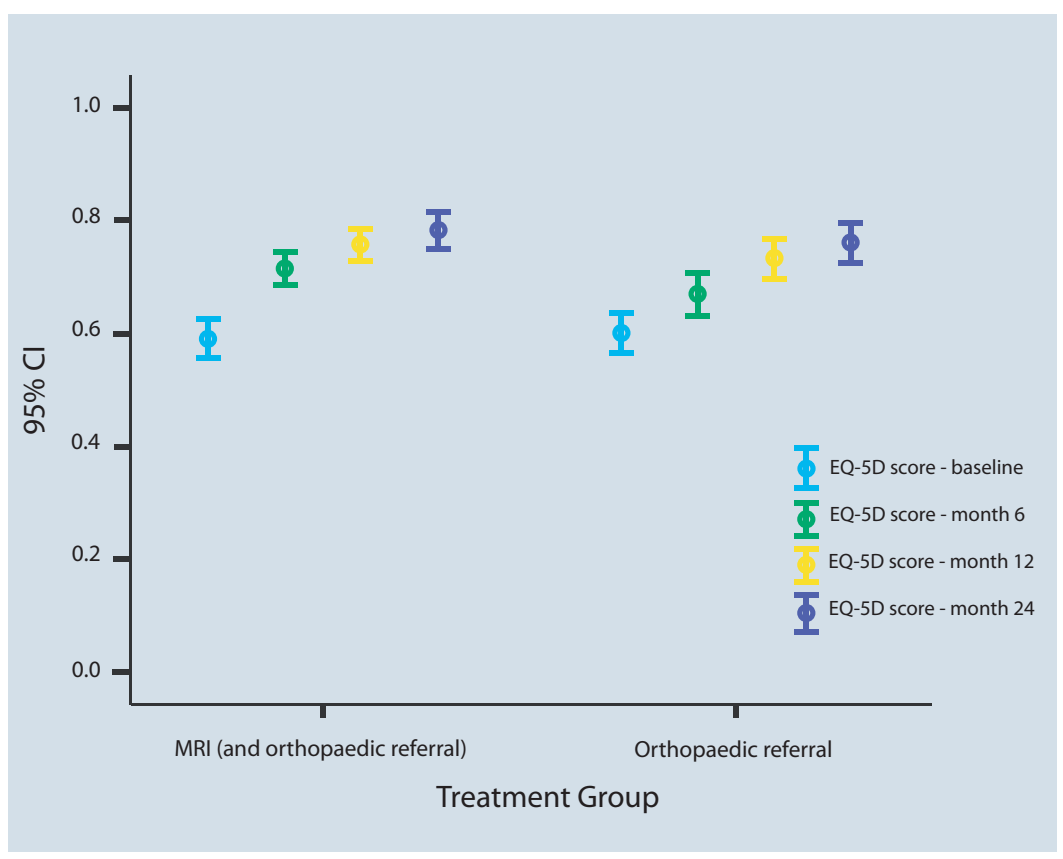

Figure 1. Mean EQ-5D scores $(95 \% \mathrm{Cl})$ over 24 months by treatment group.

Figure 2. Base-case costeffectiveness results $(5000$ bootstrap replications). those with missing data, and while it is not possible to rule out the possibility of bias, major discrepancies are not apparent.

A further potential limitation relates to the use of patient self-report questionnaires for the collection of resource use and quality of life data. While such methods can be subject to recall bias, it is nevertheless a practical way to obtain comprehensive data on healthcare resource use and is widely used in trial-based studies.

The broad validity of this method has been established empirically. ${ }^{27,28}$ Further, given the lack of blinding, the quality of life data may reflect perceived benefits associated with early access to MRI, rather than real health improvements.

Finally, from a policy perspective it is important to emphasise that these results are relevant to the UK NHS, and extrapolation to other settings must involve due caution. Further, it is important to bear in mind that UK waiting times for MRI and orthopaedic referrals have been reduced over recent years as a result of various government initiatives.

If the benefit demonstrated in this research is predominantly from early intervention, which happened to patients in the MRI arm of the trial, then one might expect that current practice in relation to orthopaedic referral has improved since the trial was performed. Thus, the true gains from early MRI might, in a UK setting, be smaller than reported here. Further work in this area would be valuable to explore the robustness of the present results given recent policy-induced changes in health service performance.

\section{Comparison with existing literature}

Previous cost-effectiveness work in this clinical area

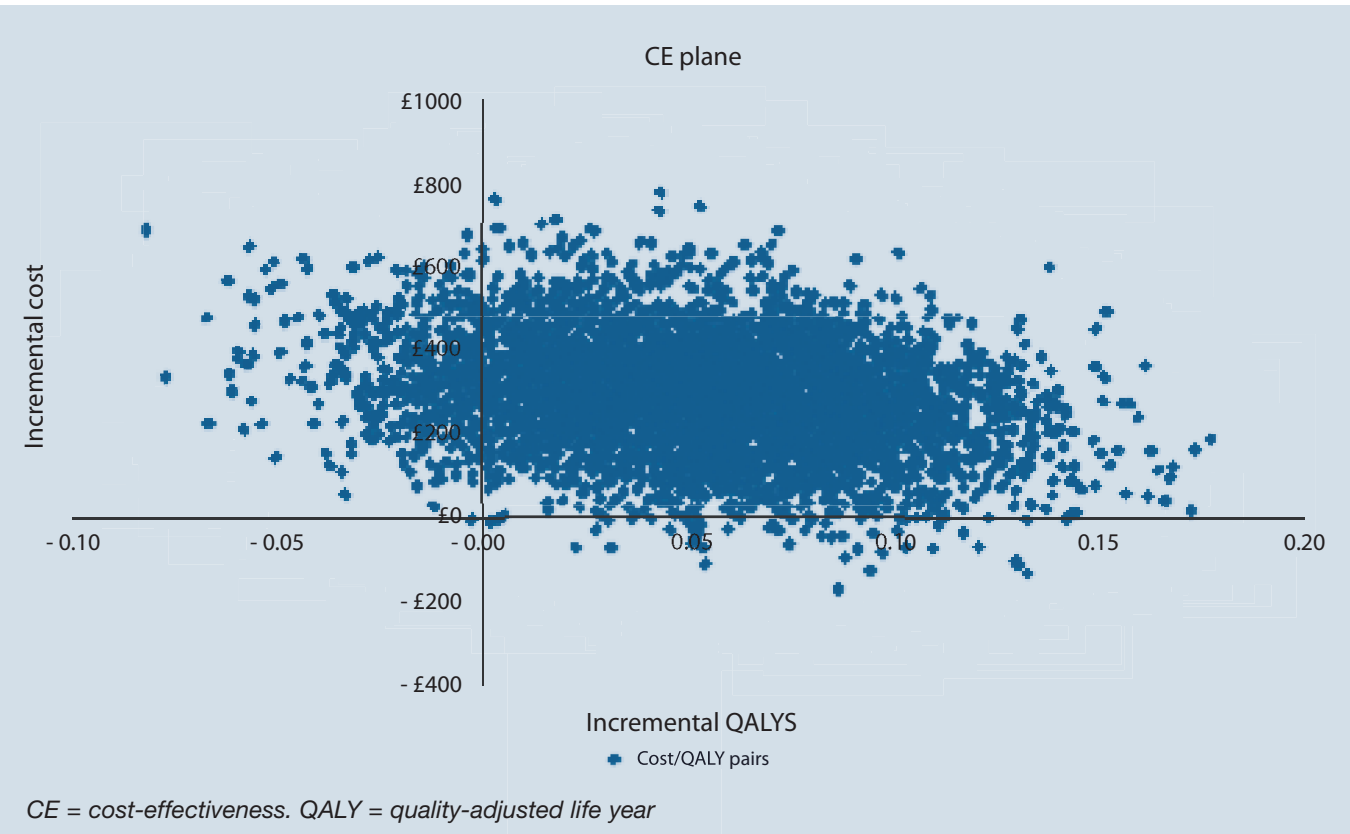




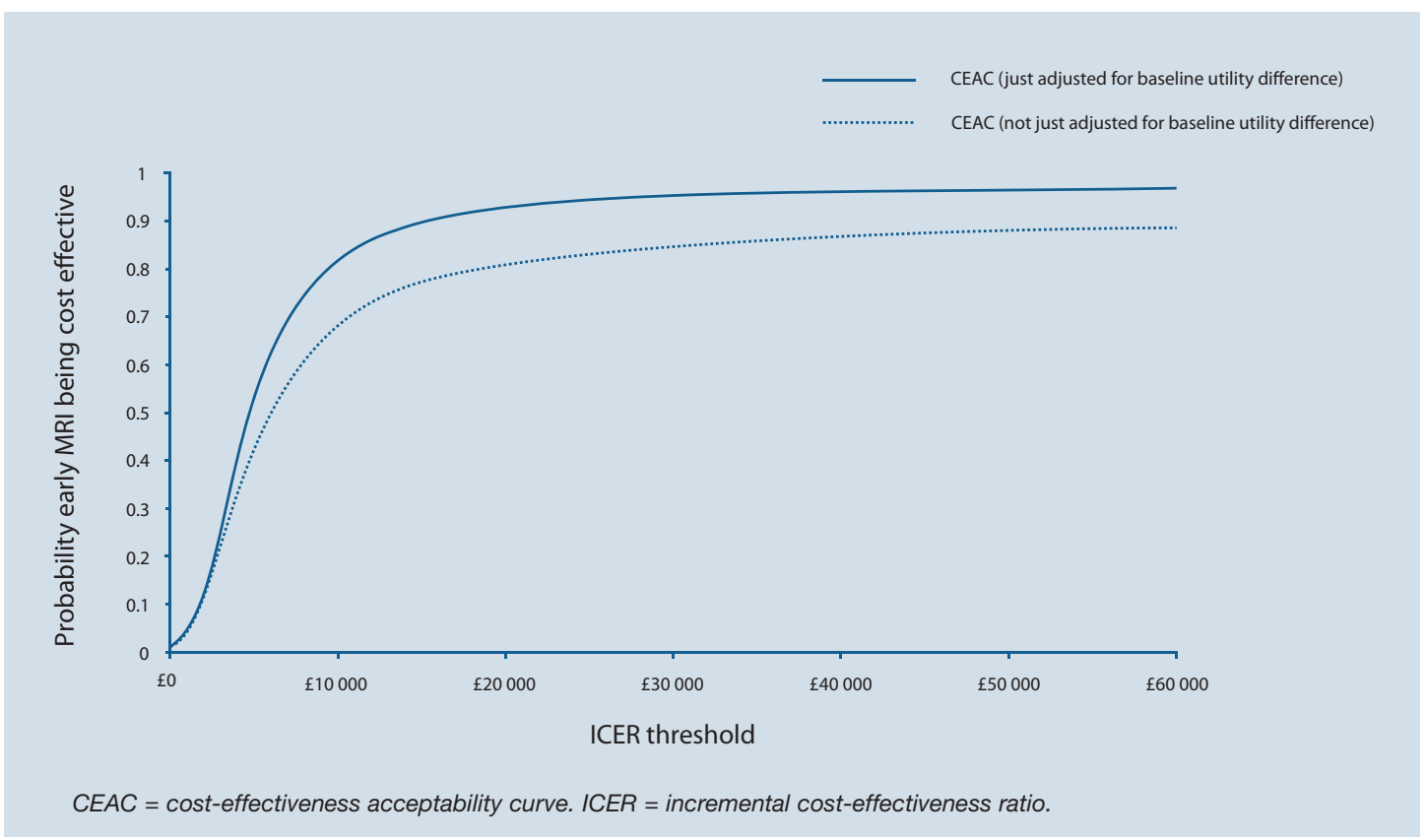

Figure 3. Cost-effectiveness acceptability curves.

has tended to concentrate on the use of MRI in patients already listed for arthroscopy, indicating that $\mathrm{MRI}$ is, at worst, cost neutral, given the avoidance of arthroscopy in many cases. ${ }^{3,10,11}$

No previous study has evaluated the costeffectiveness of direct GP referral to early MRI compared to an orthopaedic referral for patients with continuing knee problems. Thus, the present findings, of a modest increase in costs when MRI is used in such patients balanced by a small increase in QALYs, result from addressing a different clinical question and should not be seen as challenging the results from earlier work.

\section{Implications for clinical practice}

The results of this study show that timely access to $\mathrm{MRI}$ is recommended as a cost-effective use of health sector resources. The implementation of such a policy is unlikely to result in savings for the health service, but the additional cost is modest.

\section{Funding body}

Medical Research Council/Department of Health Primary Care Initiative - Second Call for Proposals (Project Number G0001133). International Standardised Randomised Controlled Trial Number 52135255. The NHS in England, Scotland, and Wales funded the excess treatment and service support costs for the timely provision of MRI and orthopaedic consultation

\section{Ethical approval}

Northern and Yorkshire Multi-Centre Research Ethics Committee approved the study (MREC/1/3/59)

\section{Competing interests}

The authors have stated that there are none

\section{Acknowledgements}

We are indebted to the patients who agreed to take part in our study. The contribution of staff in primary and secondary care to the recruitment of patients and collection of data is greatly appreciated, as is the advice and support from the Trial
Steering Committee. All members of the DAMASK trial team include Lazaros Andronis, Christine Atwell, Stephen Brealey, Stirling Bryan, Sue Collins, Helen Cox, Ben Cross, Simon Coulton, Fiona Fylan, Andrew Garratt, Fiona Gilbert, Maureen Gillan, Maggie Hendry, Kerenza Hood, Helen Houston, David King, Veronica Morton, Jo Orchard, Michael Robling, lan Russell, David Torgerson, Val Wadsworth, and Clare Wilkinson. The following is a list of all clinical collaborators who contributed to designing and delivering presentations at the educational seminars and who supported the trial at their respective NHS sites: Dr David Fowler, GP at Kincoth Medical Practice, Aberdeen; Mr Tom Scotland, Consultant Orthopaedic Surgeon, Grampian University Hospitals NHS Trust; Dr Graeme Houston, Consultant Radiologist, Ninewells Hospital, Dundee; Dr Graeme Foubister, Consultant Orthopaedic Surgeon, Ninewells Hospital, Dundee; Dr A Ross, GP, Brechin Medical Practice, Brechin; Dr lan Beggs, Consultant Radiologist, Royal Infirmary, Edinburgh; Dr John Keating, Consultant Orthopaedic Surgeon, Royal Infirmary, Edinburgh; Dr Harry Burnett, GP, Oxgangs Path Surgery, Edinburgh; Dr Nefyn Williams, General Practitioner, Llanfairfechan Health Centre; Dr Malcolm Greensmith, Consultant Radiologist, Wrexham Maelor Hospital NHS Trust; Mr James Wootton, Consultant Orthopaedic Surgeon, Wrexham Maelor Hospital NHS Trust; Mr Aloysius Mbako, Orthopaedic Surgeon, Wrexham Maelor Hospital NHS Trust; Dr Robert Byrne, Consultant Radiologist, Glan Clwyd Hospital NHS Trust; Dr David Widdowson, Consultant Radiologist, Glan Clwyd Hospital NHS Trust; Mr Salah Bastawrous, Consultant Orthopaedic Surgeon, Glan Clwyd Hospital NHS Trust; Dr Catrin Barwick, Consultant Radiologist, Ysbytty Gwynedd; Mr Luke McSweeney, Consultant Orthopaedic Surgeon, Ysbytty Gwynedd; Dr John Moroney, GP at Minster Health, York; Mr Anthony Gibbon, Consultant Orthopaedic Surgeon, York NHS Trust; Dr Mark Brook, GP, Wrose Health Centre, Bradford; Dr David Ennion, Consultant Radiologist, Bradford Royal Infirmary, Bradford; Mr Stephen Bollen, Consultant Orthopaedic Surgeon, Bradford Royal Infirmary, Bradford; Dr Julie Kitlowski, GP, St Ann's Medical Centre, Rotherham; Dr Sue Varkey, Consultant Radiologist, Rotherham General Hospital, Rotherham; Ms Amanda Rees, Consultant Orthopaedic Surgeon, Rotherham General Hospital, Rotherham; Dr Robert Cooper, Consultant Radiologist, Northern General Hospital, Sheffield; Mr Jeremy Brown, Consultant Orthopaedic Surgeon, Northern General Hospital, Sheffield; Dr Dan Roper, GP, Springhead Medical Centre, Hull; Dr Damien Taylor, Consultant Radiologist, Hull Royal Infirmary, Hull; Mr Frank Howell, Consultant Orthopaedic Surgeon, Hull Royal Infirmary, Hull. 


\section{Discuss this article}

Contribute and read comments about this article on the Discussion Forum: http://www.rcgp.org.uk/bjgp-discuss

\section{REFERENCES}

1. NHS Executive. NHS R\&D strategic review: annex on primary care. London: NHS Executive, 1999.

2. Office of Population Censuses and Surveys. Morbidity statistics from general practice: fourth national study 1991-92. London: Office for National Statistics, 1995.

3. Suarez-Almazor ME, Kaul P, Kendall CJ, et al. The costeffectiveness of magnetic resonance imaging for patients with internal derangement of the knee. Int J Technol Assess Health Care 1999; 15(2): 392-405.

4. Mackenzie R, Palmer CR, Lomas DJ, Dixon AK. MRI of the knee: diagnostic performance studies. Clin Radiol 1996; 51(5): 251-257.

5. Oei EHG, Nikken JJ, Verstijnen ACM, et al. MR imaging of the menisci and cruciate ligaments: a systematic review. Radiology 2003; 226(3): 837-848

6. Szczepura A, Clark M. Creating a strategic management plan for magnetic resonance imaging provision. Health Policy 2000; 53(2): 91-104.

7. Department of Health Hospital Activity Statistics: Imaging and Radiodiagnostic files.

http://www.performance.doh.gov.uk/hospitalactivity/data_requests /imaging_and_radiodiagnostics.htm (accessed 2 Sep 2008).

8. Barrett A. Waiting times for scans to decrease, vows Department of Health. BMJ 2005; 331(7511): 256

9. Watura R, Lloyd DCF, Chawda S. MRI of the knee: direct access for GPs. BMJ 1995; 311(7020): 1614

10. Bryan S, Bungay HP, Weatherburn G, Field S. Magnetic resonance imaging for investigation of the knee joint: a clinical and economic evaluation. Int J Technol Assess Health Care 2004; 20(2): 222-229.

11. Weinstabl R, Muellner T, Vecsei V, et al. Economic considerations for the diagnosis and therapy of meniscal lesions: can magnetic resonance imaging help reduce the expense? World J Surg 1997; 21(4): 363-368.

12. DAMASK Trial Team. Effectiveness of GP access to magnetic resonance imaging of the knee: a randomised trial. Br J Gen Pract 2008; 58(556): 767-774

13. Brealey SD, Atwell C, Bryan S, et al. The DAMASK trial protocol: a pragmatic randomized trial to evaluate whether GPs should have direct access to MRI for patients with suspected internal derangement of the knee. BMC Health Serv Res 2006; 6: 13.

14. Dolan P, Gudex C, Kind P, Williams A. A social tariff for EuroQol: results from a UK general population survey. CHE Discussion paper
138. York: Centre for Health Economics, University of York. http://www.york.ac.uk/inst/che/pdf/DP138.pdf (accessed 2 Sep 2008).

15. Billingham LJ, Abrams KR, Jones DR. Methods for the analysis of quality-of-life and survival data in health technology assessment. Health Technol Assess 1999; 3(10): 10.

16. PSSRU. Curtis L, Netten A. Unit Cost of Health and Social Care 2005. The University of Kent: Personal social services research unit, 2005. http://www.pssru.ac.uk/pdf/uc/uc2005/uc2005.pdf (accessed 2 Sep 2008).

17. Department of Health. NHS Reference Costs 2005

http://www.dh.gov.uk/PublicationsAndStatistics/Publications/Publ cationsPolicyAndGuidance/PublicationsPolicyAndGuidanceArticle /fs/en?CONTENT_ID $=4133221 \&$ chk $=$ TxHkqo $($ accessed 2 Sep 2008).

18. British Medical Association, Royal Pharmaceutical Society of Great Britain. British National Formulary. 51st edn. London: BMJ Books, 2006.

19. National Institute of Clinical Excellence. Guide to the methods of technology appraisal. London: NICE, 2004. http://www.nice.org.uk/niceMedia/pdf/TAP_Methods.pdf (accessed 24 Sep 2008).

20. Drummond MF, Sculpher MJ, Torrance GW, et al. Methods for the economic evaluation of health care programmes. 3rd edn. Oxford: Oxford University Press, 2005.

21. Barber JA, Thomson SJ. Analysis of cost data in randomised trials: an application of the non-parametric bootstrap. Stat Med 2000; 19(23): 3219-3236.

22. Efron B, Tibshirani R. An introduction to the bootstrap. New York: Chapman and Hall, 1993.

23. Briggs A, Fenn P. Confidence intervals or surfaces: Uncertainty on the cost-effectiveness plane. Health Econ 1998; 7(8): 723-740.

24. Fenwick E, Claxton K, Sculpher M. Representing uncertainty : the role of cost-effectiveness acceptability curves. Health Econ 2001; 10(8): 779-787.

25. Manca A, Hawkins N, Sculpher MJ. Estimating mean QALYs in trial-based cost-efectiveness analysis: the importance of controlling for baseline utility. Health Econ 2005; 14(5): 487-496.

26. Rawlins MD, Culyer AJ. National Institute for Clinical Excellence and its value judgements. BMJ 2004; 329(7569): 224-227.

27. Coyle D, Lee K, Drummond M. Comparison of alternative sources of data on health service encounters. J Health Serv Res Policy 1999; 4(4): 210-214

28. Petrou S, Murray L, Cooper P, Davidson LL. The accuracy of selfreported healthcare utilisation in health economics studies. In $\mathrm{J}$ Technol Assess Health Care 2002; 18(3): 705-710. 